\title{
Hepatocyte apoptotic index and p53 expression in obstructive jaundice rats
}

\author{
Kosar $\mathrm{NM}^{1}$, Tosun $\mathrm{M}^{2}$, Polat $\mathrm{C}^{3}$, Kahraman $\mathrm{A}^{4}$, Arikan $\mathrm{Y}^{5}$ \\ Afyon Kocatepe University, Faculty of Medicine, Department of Surgery, Afyonkarahisar, Turkey. \\ coskunpolat2001@yahoo.com
}

\begin{abstract}
Objective: Obstructive jaundice is a serious disease. It can detoriate critical functions in the liver. Material and method: A total of 20 male Wistar-Albino rats were randomly allocated into two groups consisting of ten in each as follows: Group I (Control) was subjected to a sham operation isolating the bile duct. Group II(Study) was subjected to acute cholestasis induced by bile duct ligation with $4 / 0$ silk suture from two different places and full fold cut between ligatures. On the 7th day, group II rats were re-operated for liver sampling and sacrification-aimed histological analysis through the old incision with anaesthesia. Hepatic tissues were histologically and immunohistochemically processed. The number of apoptotic and p53(+) cells were measured. Results: On the 7th day, the averages of direct and indirect bilirubin values in Group II rats were found to be 6.99 and $11.70 \mathrm{mg} / \mathrm{dl}$, respectively. They were observed to be statistically significant. In the immunohistochemical evaluation p53 expression in hepatocytes was assessed, p53-positive hepatocytes were determined to exist quite widely in the tissue samples taken from the livers of rats in the study group. Nevertheless, no cells exhibiting p53 expression were found in the tissue samples of the control group.

Conclusion: Apoptosis is a closed box and it might make it possible to stop the many disesase processes or accelerate the healing. If the principal effective mechanism in the liver under a certain stress factor is apoptosis, it is definite that it will make a difference in the treatment approach. Consequently, we can say that both apoptotic index and p53 expression increase in the rats' liver with biliary obstruction (Fig. 4, Ref. 51). Text in PDF www.elis.sk.

Key words: apoptosis, p53, biliary obstruction.
\end{abstract}

Biliary obstruction is a frequently seen serious surgical pathology which may occur due to extrahepatic or intrahepatic causes. Despite significant advances in diagnostic and treatment procedures especially in the last decade, this pathology remains with high morbidity and mortality rates. Biliary obstruction is reported to be responsible for morbidity and mortality rates of numerous complications, including cardiovascular dysfunction, renal failure, gastrointestinal hemorrhage, coagulopathy and sepsis due to obstructive jaundice $(1,2)$.

Apoptosis is a programmed mechanism of cell death caused by various physiological and pathological conditions in DNA dependent cells (3). Especially skin, intestinal and immune-system cells, many tissues require apoptosis for a regular regeneration (4-8). In apoptosis hepatocytes extend the cell cycle by activating the p53 gene in their own nuclei and try to resolve the DNA damage in order to decrease or eliminate the impact of the cel-

${ }^{1}$ Afyon Kocatepe University, Faculty of Medicine, Department of Surgery, Afyonkarahisar, Turkey, ${ }^{2}$ Afyon Kocatepe University, Faculty of Medicine, Department of Histology, Afyonkarahisar, Turkey, ${ }^{3}$ Karabuk University, Faculty of Medicine, Department of Surgery, Karabuk, Turkey, ${ }^{4}$ Akdeniz University, Faculty of Medicine, Department of Pathology, Afyonkarahisar, Turkey, and ${ }^{5}$ Afyon Kocatepe University, Faculty of Medicine, Department of Biochemistry, Afyonkarahisar, Turkey

Address for correspondnece: C. Polat, MD, Ali ihsan Pasa Mah. Akay Cad. Gunhan Sitesi No:5/1 03200, Afyonkarahisar, Turkey.

Phone: +90.505 .2664500$ lular damage (9-11). DNA damage in the cell can be completely resolved through p53 or in the case of a great damage, apoptotic signaling mechanisms can be activated, forcing the cells to selfdestruction (12). Increase in the number of apoptotic cells in this process creates a protective effect in the body. If the cell does not die with apoptosis, then the damage to DNA becomes permanent and several changes in the cell end up in cancer development, presenting with various clinical pictures $(13,14)$.P53 functions through its direct or indirect interactions in the cellular processes such as the control of gene transcription, DNA repair, cell cycle control, genomic stability, chromosome segregation, senescence, angiogenesis, apoptosis and tumor suppression (15).

Apoptosis and p53 expression have been studied in a few physiological and pathological situations (16-8). To our knowledge, apoptosis response and p53 expression in the septicemia process which significantly affects the morbidity and mortality in obstructive jaundice are not clear.

Therefore, in this study we aimed to histologically define the liver level of apoptosis in rats with experimentally induced biliary obstruction.

\section{Materials and methods}

Animals

A total of 20 male, Wistar-Albino rats weighing 270-320 $\mathrm{g}$ which has been obtained from Suleyman Demirel University 
Experimental Investigation Center, Isparta, were used in the present study. They were kept at temperatures between 20 and $25^{\circ} \mathrm{C}$, with relative humidity between $40 \%$ and $70 \%$, and 12 -hour light and dark cycles, with standard rat food and water ad libitum. Adequate hydration was ensured for all animals. At the beginning of the experiment, each rat was given a number from 1 to 20. The rats were chosen randomly and put into separate cages for each group.

\section{Experimental design}

The design was randomised controlled trial with blind outcome assesment and the study was performed in accordance with $\mathrm{Na}$ tional Institutes of Health and approved by Kocatepe University Animal Ethics Committee.

\section{Anesthesia}

All rats were anaesthetised at the beginning of the experimental procedures with an intramuscular injection of ketamine $\left(5 \mathrm{mg} / \mathrm{kg}\right.$, ketamin hydrochloride, Ketalar ${ }^{\circledR}$; Eczacibası-Werner Lambert, Istanbul, Turkey). Additional anaesthetic doses were given when required during the course of the procedure $(1 \mathrm{mg} /$ $\mathrm{kg}$, intramuscular).

\section{Surgical procedure}

After achieving anesthesia, the animals were placed in a supine position with limbs attached to the operation table. After shaving the abdomen with safety razor and disinfecting with povidone iodine solution (Batticon; Trommsdorff-Adeka Ilac Sanayi, Samsun, Turkey) a $3 \mathrm{~cm}$ midline incision was made from xiphoides to pubis.

The rats were randomised to two groups, each consisting of eight rats:

Group I(control) was subjected to a sham operation.

Group II(study group), extra hepatic cholestasis was induced by double ligation and section of the common bile duct with $4 / 0$ silk suture (Dogsan, Istanbul, Turkey). In this group, animals received $1 \mathrm{~mL} \% 0.9 \mathrm{NaCl}$ twice a day intraperitoneally (i.p.). On the seventh day, blood samples were collected for biochemical assays and sacrificied from the same laparotomy place under ether anesthesia. Small liver sections from the same lobe of liver from each rat were fixed in $10 \%$ neutral formalin.

\section{Histology}

For histology, formalin fixed specimens were dehydrated, cleared and embedded in paraffin. Serial sections of $4 \mu$ thick were cut from these blocks and put onto poly-L-lysine coated slides (labvision Corp., Fremont, CA) for immunohistochemistry. All the slides were evaluated by a blinded observer.

The p53(+) and apoptotic cells in the liver stroma were counted in 10 different places at X 20 objective magnification by the light microscope (10 sections from each rat were used). UTHSCSA Image Tool Image Analysis Programme was used for the cell count.

\section{Immunohistochemistry}

For detecting p53(+) cells, the slides were deparaffinised in a $65{ }^{\circ} \mathrm{C}$ incubator. They were then rehydrated by decreasing alcohol series. For antigen retrieval, microwave treatment was used in 10 $\mathrm{mM}$ citrate buffer (Labvision Corp.) with $\mathrm{pH}$ 6.0. After the retrieval process, $10 \% \mathrm{H}_{2} \mathrm{O}_{2}$ (Sigma, St Louis, MO) was used for inactivation of endogenous peroxidase in the specimens. Specimens were then reacted with rabbit polyclonal antibody against human p53 protein (Labvision Corp.) The primary antibody and HRP (Horse Radish Peroxydase) detection system (Labvision Corp.) The secondary antibody and AEC substrate system (Labvision Corp.) for chromogen. Mayers haematoxylin (Sigma) was used for counter staining. All the slides were dehydrated and mounted with aqueous mounting solution (Labvision Corp.) and evaluated under a light microscope (Nikon Eclipse E600, Japan).

For detecting apoptosis, a TUNNEL-based commercial apoptosis kit (Fragel DNA fragmentation kit, Calbichem, Darmstadt, Germany) was used. Positive control slides supported by the manufacturer were used for the control (19).

\section{Statistical analysis}

Biochemical analysis in all groups was performed in the blood on the seventh day. Values were expressed as mean \pm standard deviation (SD). For statistical analysis, SPSS for Windows 15.0 program was used. Mann-Whitney U test was used for the statistical comparison of the groups' bilirubin values. A value of $\mathrm{p}<$ 0.05 was accepted as statistically significant. Statistical analysis of immunosupressive evaluation was not performed, because the number of immunosupressive cells in group I (control) was 0 .

\section{Results:}

Biochemical analysis in the group II was performed on the 7 th day. The averages of direct and indirect bilirubin values in the Group II were found as $6.99 / 11.70 \mathrm{mg} / \mathrm{dl}$, respectively. They were observed to be statistically significant with respect to the control group $(\mathrm{p}=0.001)$.

In the light microscopic evaluation of apoptotic cells in the liver, apoptotic cells were observed to widely exist in the liver tissue and it was determined that they exhibited dense accumulation in some regions (Fig. 1). Nevertheless, no apoptotic cell was seen in the liver tissue of the rats in the control group (Fig. 2).

In the immunohistochemical evaluation of p53 expression in hepatocytes, p53 (+) hepatocytes were determined to exist quite widely in the tissue samples taken from the livers of rats in the study group (Fig. 3). However, no cells exhibiting p53 expression were found in the tissue samples of the control group (Fig. 4).

\section{Discussion}

Obstructive jaundice may occur due to numerous causes. This may contribute to development of many pathophysiological processes, resulting in significant rates of complications, morbidity and mortality. There are different approaches used for its treatment. Hepatectomy is one of the most preferred methods. In the rats with obstructive jaundice undergoing hepatectomy, postoperative liver regeneration was found similar to that of the sham group, while the rates of morbidity and mortality were higher $(20,21)$. 


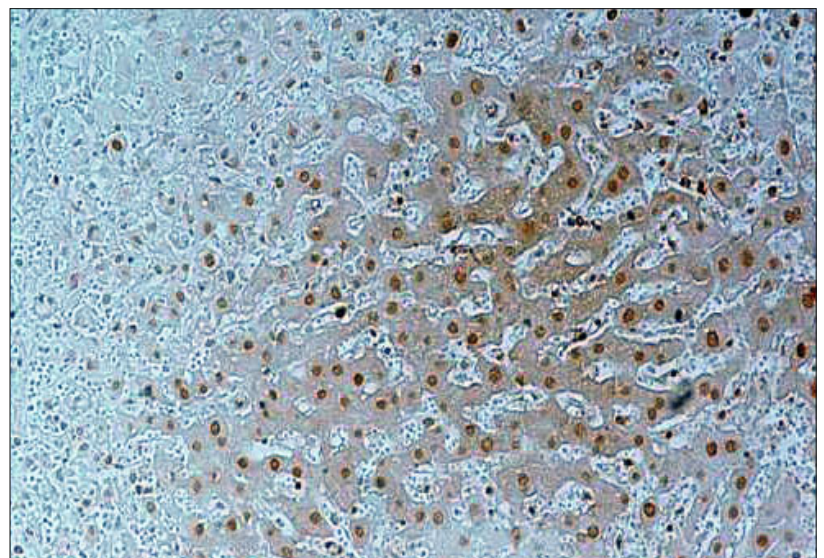

Fig. 1. Apoptotic cells(arrows) in liver tissues of Group II(Study group) (X200). Fragel (Calbiochem). Blue fitler was used.

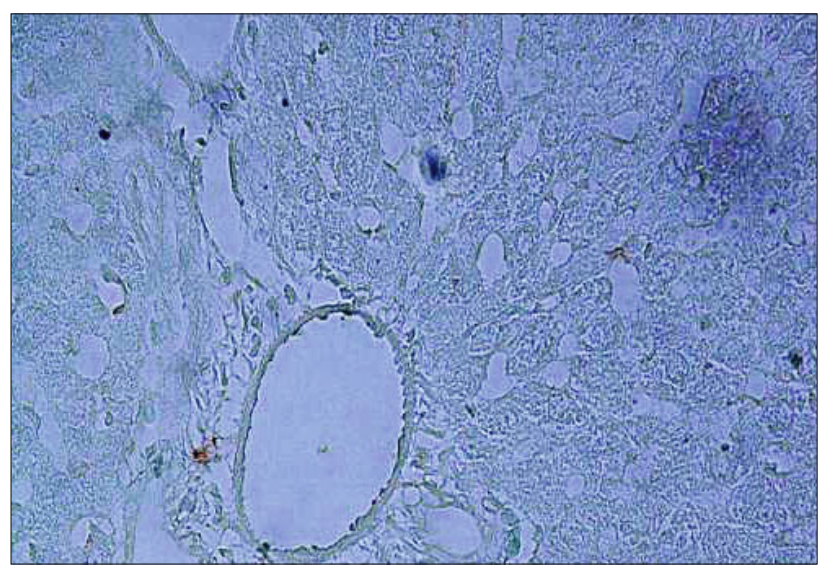

Fig. 2. Apoptotic cells in liver tissues of Group I (Control group) (X200). Fragel (Calbiochem). There was no apoptotic cell. Blue filter was used.

Many factors have been accused for the increase in morbidity and mortality in obstructive jaundice, including hypotension, impaired nutritional status, depressed immune system, hepatic dysfunction and bile salts in circulation (22-24). Furthermore, impairment of wound healing, development of portal and systemic endotoxemia, decreased reticuloendothelial cell functions, reduced $\mathrm{T}$ cell response, depression in non-specific cellular immune response, decreased bacterial clearance and increased bacterial translocation are also accused $(25,26)$. In addition, role of the problems occurring in immunosuppression resulting from the damage to functional cells has been also described $(27,28)$.

It was noteworthy in our study that the possibility of significant apoptosis and p53 expression might explain these rates of morbidity and mortality. That is why we believe that triggering of the apoptosis process was crucial in the obstruction icterus rather than prominent necrosis formation. Despite similar rates of regeneration in both groups, it is yet to be explained whether the high mortality rate in the study group resulted from a difference between the groups in the triggered apoptosis process or was caused by a difference at the genetic level. This is why we aimed to study p53 expression also.

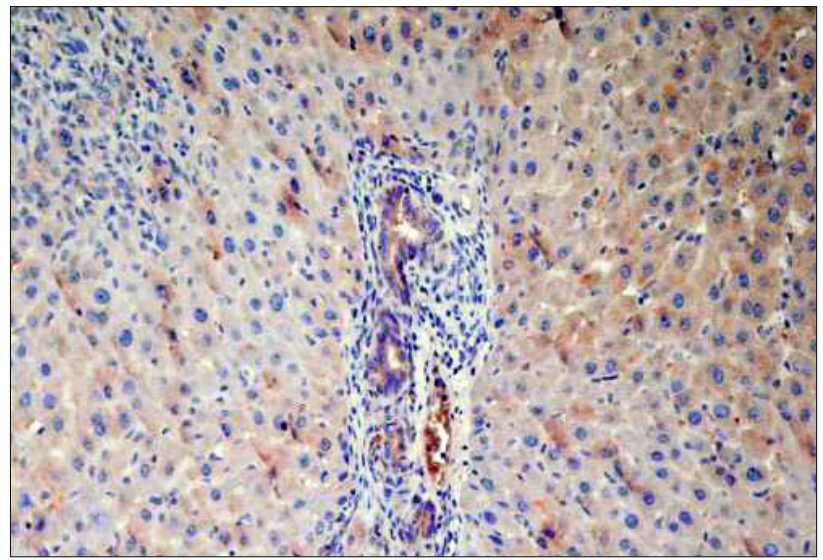

Fig. 3. The p53 (+) cells (with red cytoplasm) in liver tissues of Group II (Study group). p53 Clone DO7 (Labvision). X200.

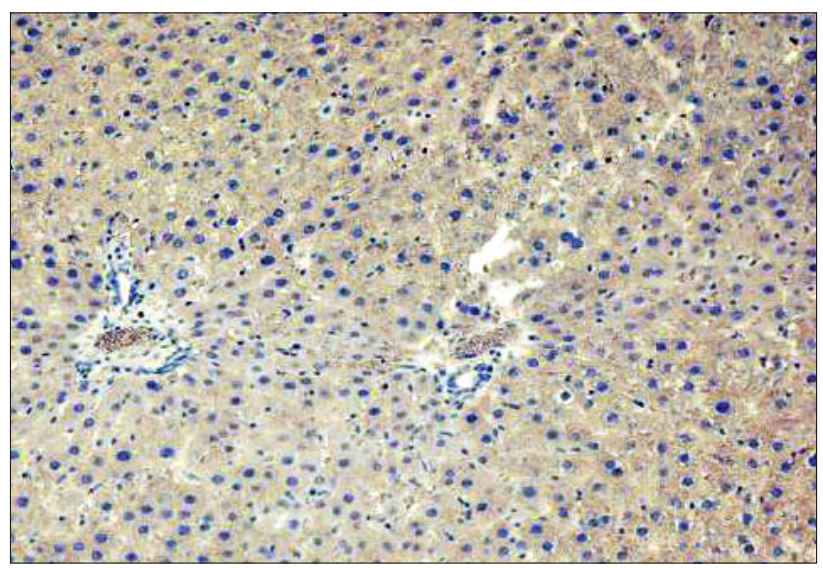

Fig. 4. The parenchyma in liver tissue samples of Group I(Control group). There were no p53(+) cell. p53 Clone DO7 (Labvision). X200.

Obstructive jaundice is reported not only to cause weakening of the hepatic cell functions, but also to produce a depression in Kupffer cell activity, which is a part of immune system, eventually resulting in hepatic damage and portal hypertension $(29,30)$. In our study, we also investigated the association with the source of depression in Kupffer cell activity, which is thought to increase morbidity and mortality with the apoptotic process of the icteric situation in the liver. We wanted to pay the way for giving time to the physician by slowing the process with a medical intervention in this pathway triggered during the icterus, if we could define to which extend the apoptosis was affected.

Different stimuli such as severe hypoxia, DNA damage, heat shock protein, metabolic changes and certain cytokines activate different tumor suppressor gene types and those will stabilize the genome (31). Today, p53 protein was demonstrated to be the major tumor suppressor gene. P53 protein expression was found with very low levels in the normal, non-stressed cells, but p53 protein becomes stabilized after stress situations and accumulates in the nucleus to maintain the genomic stability. If this process fails to block DNA damage, p53 protein stimulates apoptosis which is defined as the pattern of changes at molecular and morphological 
level known as the "programmed cell death" (32-35). Looking at the basis of hepatocyte damage and progression of the liver disease, we encounter with the studies advocating the role of direct chemical damage to hepatocyte by toxic hydrophobic bile salts (36-38). These studies report that retention of the biliary components and high biliary pressures also play important roles in obstructive jaundice. Hepatic levels of toxic bile salts, chenodeoxycholic acid and deoxycholic were found to be directly associated with the degree of liver damage $(39,40)$. Again a diffuse necrosis is not remarkable in cholestatic liver disease and apoptosis response is reported to be more important than cholestatic necrosis in the hepatocyte death process (41). Events occurring in the bile salts toxicity typically include the swelling of hepatocytes, impairment of the membrane integrity and dissolution of the intracellular components. It is reported that toxic bile acids themselves can also directly lead to apoptosis out of these reactions (42). In our study, we found a marked increase in the number of apoptotic cells that was not seen in the controls. We believe that this was caused by bacterial translocation resulting from the accumulation of toxic hydrophobic bile salts in hepatocyte with endotoxins in the circulation.

Similar to our study, Sheen-Chen et al also reported that ductal proliferation was significantly increased with the apoptosis response in the subjects undergoing hepatic duct ligation (43). Again, Parks et al reported that intestinal mucosa exposed to atrophy, density and thickness of the villus were decreased and the rate of apoptosis was significantly increased in distal ileal cells (44).

Apoptosis causes the activation of fas pathway as well as triggers the activation of caspases, which are intracellular enzymes (45). Apoptosis induced by the bile salts causes the activation and translocation of protein kinase $\mathrm{C}$, resulting in an increase of the intracellular magnesium level $(46,47)$.Thus, Mg-dependent endonucleases lead to DNA division. Therefore, apoptotic cell death is thought to play a central role in many physiological and pathophysiological processes $(48,49)$. Considering increased apoptosis and p53 expression, we can say that apoptosis and p53 have a central role in the existing pathophysiology.

Distribution of the mature cell types in the epithelium occurs depending on different stages such as proliferation and differentiation of the cells and programmed cell death. This balance may alter with the epithelial damage and some cells which are affected more easily from the programmed cell death can be repaired by the other cells voluntarily contributing to tissue regeneration $(50,51)$. This means another effective point in the programming of apoptosis to be hidden in the genetic coding. Therefore, we also studied p53 gene, which is associated with apoptosis. In our study, no p53 expression was detected in the control group, while we showed a marked $\mathrm{p} 53$ response in the study group.

In summary, the present study demonstrated that a serious cellular damage occurs in the hepatocyte with biliary obstruction, and the hepatocytes extend their cell cycle by activating the p53 gene in their own nuclei and try to resolve the DNA damage.

\section{References}

1. Orrego H, Carmichael FJ, Phillips MJ. Protection by propylthouracil against carbon tetrachloride induced liver damage. Gastroenterology 71; 1976 (5): 821-826.

2. Ozsoy Y, Ozsoy M, Coskun T, Namli K, Var A, Özyurt B. The effects of $\mathrm{L}$-arginine on liver damage in experimental acute cholestasis an Immunohistochemical Study. HBP Surgery 2011: 306069. Epub 2011 Jun 1 (in press).

3. Sun EW, Shi YF. Apoptosis: the quiet death silences the immune system. Pharmacol Ther 2001; 92: 135-145.

4. Hengartner MO. The biochemistry of apoptosis. Nature 2000; 407: 770-776.

5. Gren DR. Apoptotic pathways: paper wraps stone blunts scissors. Cell 2000; 102: 1-4.

6. Baumann S, Krueger A, Kirchhoff S, Krammer PH. Regulation of T cell apoptosis during the immune response. Curr Mol Med 2002; 2: $257-272$.

7. Hotchkiss RS, Tinsley KW, Karl IE. Role of apoptotic cell death in sepsis. Scand J Infect Dis 2003; 35: 585-592.

8. Mahidhara R, Billiar TR: Apoptosis in sepsis. Crit Care Med 2000; 28: $105-13$.

9. Gottlieb TM, Oren M. p53 in growth control and neoplasia. Biochim Biophys Acta 1996; 1287 (2-3): 77-102.

10. Donehower LA. Effects of p53 mutation on tumor progression: Recent insights from mouse tumor models Biochim Biophys Acta 1996; 1242 (3): 171-176.

11. Ding, HF, Fisher DE. Mechanisms of p53-mediated apoptosis. Crit Rev Oncog 1998; 9: 83-98.

12. Sherr CJ. Tumor surveillance via the ARF-p53 pathway. Genes Dev 1998; 12: 2984-2991.

13. Zhang Y, Xiong Y, Yarbrough WG. ARF promotes MDM2 degradation and stabilizes p53: ARF-INK4a locus deletion impairs both the Rb and p53 tumor suppression pathways. Cell 1998; 92: 725-734.

14. Sherr CJ, Weber JD. The ARF/p53 pathway. Curr Opin Genet Dev 2000; 10: 94-99.

15. Bénard J, Douch-Rasy S, Ahomadegbe JC. TP53 Family Members and Human Cancers. Hum Mutat 2003; 21; 182-191.

16. Wang DS, Dou KF, Li KZ, Gao ZQ, Song ZS, Liu ZC. Hepatocellular apoptosis after hepatectomy in obstructive jaundice in rats. World $\mathrm{J}$ Gastroenterol 2003; 9: 2737-2741.

17. Arikan Y, Tosun M, Volkan Ş, Kalkan S, Erdem S. p53 expression and apoptosis in liver and spleen during $\mathrm{CO} 2$ pneumoperitoneum. Langenbecks Arch Surg 2008; 393 (6): 877-882.

18. Daemen MA, van't Veer C, Denecker G, Heemskerk VH, Wolfs TG, Clauss M, Vandenabeele P, Buurman WA. Inhibition of apoptosis induced by ischemia- reperfusion prevents inflammation. J Clin Invest $1999 ; 79 ; 521-541$.

19. Arioz DT, Tosun M, Polat C, Saylan A, Yilmazer M. The effects of ischaemic preconditioning on ovarian apoptosis and $\mathrm{p} 53$ expression during laparoscopy. J Obstet Gynaecol 2012; 32 (5): 467-471.

20. Moritz M, Snodgrass PJ. Serun enzymes derived from liver cell fractions. Responses to bile duct ligation in the rats. Gastroenterology 1972; 62: 93-100. 
21. Foss A, Andersson R, Ding JW. Effect of bile obstruction on liver regeneration following major hepatectomy: an experimental study in the rat. Eur Surg Res 1995; 27: 127-133.

22. Greve JW, Gouma DJ, Soeters PB, Buurman WA. Suppression of cellular immunity in obstructive jaundice is caused by endotoxins: a study with germ-free rats. Gastroenterology 1990; 98: 478-485.

23. Ito Y, Machen NW, Urbaschek R, McCuskey RS. Biliary obstruction exacerbates the hepatic microvascular inflammatory response to endotoxin. Shock 2000; 14: 599-604.

24. Yerushalmi B, Dahl R, Devereaux MW, Gumpricht E, Sokol RJ. Bile acid on induced rat hepatocyte apoptosis is inhibited by antioxidants and blockers of the mitochondrial permeability transition. Hepatology 2001; 33: 616-626.

25. Kimmings AN, van Deventer SJ, Obertop H, Rauws EA, Huibregtse K, Gouma DJ. Endotoxin, cytokines, and endotoxin binding proteins in obstructive jaundice and after preoperative biliary drainage. Gut 2000; 46: 725-731.

26. Megison SM, Dunn CW, Horton JW, Chao H. Effects of relief of biliary obstruction on mononuclear phagocyte system function and cell mediated immunity. Br J Surg 1991; 78: 568-571.

27. Sun EW, Shi YF. Apoptosis: the quiet death silences the immune system. Pharmacol Ther 2001; 92: 135-145.

28. Hotchkiss RS, Tinsley KW, Karl IE. Role of apoptotic cell death in sepsis. Scand J Infect Dis 2003; 35: 585-592.

29. Daglar GO, Kama NA, Atli M, Yuksek YN, Reis E, Doganay M, Dolapci M, Kologlu M. Effect of 5-lipoxygenase inhibition on Kupffer cell clearance capacity in obstructive jaundiced rats. J Surg Res 2001; 96: $158-162$.

30. Zimmermann H, Reichen J, Zimmermann A, Sagesser H, Thenisch B, Hoflin F. Reversibility of secondary biliary fibrosis by biliodigestive anastomosis in the rat. Gastroenterology 1992; 103: 579-589.

31. Levine AJ. P53, the cellular gatekeeper for growth and division. Cell 1997; 88: 323-331.

32. Chipuk JE, Green DR. Dissecting p53-dependent apoptosis. Cell Death Differentiation 2006; 113: 1396-1402.

33. Liying Yang and Steven D. Leach Charles R. Scoggins, Ingrid M. Meszoely, Michihiko Wada, Anna L. Means. p53-Dependent acinar cell apoptosis triggers epithelial proliferation in duct-ligated murine pancreas. Am J Physiol Gastrointest Liver Physiol 2000; 279: 827-836.

34. El-Deiry WS. Regulation of $\mathrm{p} 53$ downstream genes. Semin Cancer Biol 1998; 8: 345-357.

35. Miyashita T, Reed JC. Tumor suppressor $\mathrm{p} 53$ is a direct transcriptional activator of human bax gene. Cell 1995; 80: 293-299.

36. Rodrigues CM, Steer CJ. Mitochondrial membrane perturbations in cholestasis. J Hepatol 2000; 32: 135-141.
37. Benz C, Angermuller S, Tox U, Kloters-Plachky P, Riedel HD, Sauer P, Stremmel W, Stiehl A. Effect of tauroursodeoxycholic acid on bile-acid induced apoptosis and cytolysis in rat hepatocytes. J Hepatol 1998; 28: 99-106.

38. Faubion WA, Guicciardi ME, Miyoshi H. Toxic bile salts in-duce rodent hepatocyte apoptosis via direct activation of Fas. J Clin Invest 1999; 103: 137-145.

39. Trauner M, Meier PJ, Boyer JL. Molecular regulation of hepatocellular transport systems in cholestasis. J Hepatol 1999; 31: 165-178.

40. Schmucker DL, Ohta M, Kanai S, Sato Y, Kitani K. Hepatic injury induced by bile salts: correlation between biochemical and morphological events. Hepatology 1990; 12: 1216-1221.

41. Patel T, Gores GJ. Apoptosis and hepatobiliary disease. Hepatology 1995; 21: 1725-1741.

42. Takikawa Y, Miyoshi H, Rust C, Roberts P, Siegel R, Mandal PK, Millikan RE, Gores GJ. The bile acid-activated phosphatidylinositol 3-kinase pathway inhibits fas apoptosis upstream of bid in rodent hepatocytes. Gastroenterology 2001; 120: 1810-1817.

43. Sheen-Chen SM, Hung KS, Ho HT, Chen WJ, Eng HL. Effect of glutamine and bile acid on hepatocyte apoptosis after bile duct ligation in the rat. World J Surg 2004; 28: 457-460.

44. Parks RW, Stuart Cameron CH, Gannon CD, Pope C. Changes in gastrointestinal morphology associated with obstructive jaundice. J Pathol 2000; 192: 526-532.

45. Liu XJ, Yang L, Wu HB, Qiang O, Huang MH, Wang YP. Apoptosis of rat hepatic stellate cells induced by anti-focal adhesion kinase antibody. World J Gastroenterol 2002; 8: 734-738.

46. Cong B, Li SJ, Yao YX, Zhu GJ, Ling YL. Effect of cholecystokinin octapeptide on tumor necrosis factor alpha transcription and nuclear factorkappaB activity induced by lipopolysaccharide in rat pulmonary interstitial macrophages. World J Gastroenterol 2002; 8: 718-723.

47. Jones BA, Rao YP, Stravitz RT, Gores GJ. Bile salt-induced apoptosis of hepatocytes involves activation of protein kinase C. Am J Physiol 1997; 272: G1109-G1115.

48. Hurle JM. Cell death in developing systems. Methods Archiv Exp Pathol 1988; 13: 55-86.

49. Mac Donald HR, Lees RK. Programmed cell death of autoreactive thymocytes. Nature 1990; 343: 642-644.

50. Fuchs E, Segre JA. Stem cells: a new lease on life. Cell 2000; 100: 143-155.

51. Weissman IL. Stem cells: units of development, units of regeneration, and units in evolution. Cell 2000; 100: 157-168.

Received September 8, 2012. Accepted April 8, 2014. 